\title{
CONCENTRAÇÃO INIBITÓRIA MÍNIMA DE OXITETRACICLINA PARA ISOLADOS DE Aeromonas hydrophila OBTIDOS DE DIFERENTES FONTES
}

\author{
Minimal inhibitory concentration to oxitetracycline in Aeromonas hydrophila strains isolated \\ from different sources
}

\author{
Delton José Pereira Júnior ${ }^{1}$, Henrique César Pereira Figueiredo², \\ Daniela Oliveira Carneiro ${ }^{1}$, Carlos Augusto Gomes Leal ${ }^{3}$
}

\begin{abstract}
RESUMO
Objetivou-se com este trabalho determinar a concentração inibitória mínima (MIC) de oxitetraciclina para isolados de Aeromonas hydrophila obtidos de pescado, água de cultivo de peixes e casos de septicemia hemorrágica em peixes. Foi determinado MIC de 100 isolados de A. hydrophila, oriundos de 12 pisciculturas localizadas nos Estados de Minas Gerais, Rio de Janeiro e Rio Grande do Sul, utilizando a técnica de macrodiluição em caldo. Os resultados demonstraram que 14 isolados apresentaram MIC $>100 \mu \mathrm{g} / \mathrm{mL}$ (resistentes) e 86 apresentaram MIC $\leq 12,5 \mu \mathrm{g} / \mathrm{mL}$ (sensíveis). Não houve diferença entre os isolados de pescado, caso clínico e água de cultivo. Conclui-se que a variação demonstrada pode representar um risco de seleção de linhagens bacterianas resistentes em ambientes aquáticos devido ao uso de oxitetraciclina.
\end{abstract}

Termos para indexação: Aeromonas hydrophila, oxitetraciclina, resistência a antibióticos, MIC, Brasil.

\begin{abstract}
The aim of this paper was to determine the minimal inhibitory concentration (MIC) to oxitetracycline in Aeromonas hydrophila strains isolated from marketed fish, pond water of piscicultures and fish suffering hemorrhagic septicemia. These strains were obtained from 12 different piscicultures from Minas Gerais, Rio de Janeiro e Rio Grande do Sul states. It was determined the MIC to 100 strains, using the broth macrodilution method, and the results showed that 86 strains shown value of MIC $\leq 12,5 \mu \mathrm{g} / \mathrm{mL}$ (classified as susceptible) and 14 strains presented MIC $\geq 100 \mu \mathrm{g} / \mathrm{mL}$ (classified as resistant). No differences were observed among strains isolated from marketed fish, pond water and disease outbreaks. I was concluded that the variation detected may represent a risk of selection of resistant bacterial strains in aquatic environments under use of oxitetracycline.
\end{abstract}

Index terms: Aeromonas hydrophila, oxitetracycline, antibiotic resistance, MIC, Brazil.

(Recebido para publicação em 2 de junho de 2005 e aprovado em 23 de janeiro de 2006)

\section{INTRODUÇÃO}

Aeromonas hydrophila é uma bactéria Gram negativa, ubíqua em ambientes aquáticos que causa septicemia hemorrágica em peixes de água doce e, ocasionalmente, marinhos (MERINO et al., 1995; KIROV et al., 2002; WHO, 2004). Em seres humanos, podem causar diarréias, septicemia, inflamação do tecido conjuntivo e síndrome hemolítica urêmica, especialmente em indivíduos imunossuprimidos (JANDA \& ABBOTT, 1998). Os seres humanos adquirem A. hydrophila por meio de água ou alimentos contaminados. No Brasil, grande parte do pescado produzido é comercializado in natura após abate artesanal sem um processamento adequado. Em muitos casos, a frequiência de inspeção sanitária nesses alimentos é baixa (ROUBACH et al., 2003). Este fato eleva o risco de veiculação de bactérias patogênicas ou comensais portadoras de genes de resistência aos seres humanos. A. hydrophila pode ser veiculador de genes de resistência a antibióticos para bactérias patogênicas ou não patogênicas a seres humanos e peixes.

No Brasil, o uso de oxitetraciclina em pisciculturas é amplo, sendo utilizado em tratamentos de infecções bacterianas, profilaxia ou adicionado à ração como promotores de crescimento. Apesar da ampla utilização, não há regulamentação para o uso deste tipo de droga. Este fato eleva a pressão de seleção de bactérias resistentes a este antibiótico nos sistemas de produção intensiva.

Portanto, o objetivo desse trabalho foi determinar e comparar a concentração inibitória mínima de oxitetraciclina para isolados de A. hydrophila obtidos de pescado destinado ao consumo humano, água de cultivo de peixes e casos clínicos de septicemia hemorrágica oriundos de pisciculturas do Brasil.

${ }^{1}$ Médico Veterinário, Mestre em Ciência dos Alimentos - Universidade Federal de Lavras/UFLA - Cx. P. 3037 - 37.200-000 - Lavras, MG. ${ }^{2}$ Médico Veterinário, Doutor em Microbiologia, Professor Adjunto do Departamento de Medicina Veterinária da Universidade Federal de Lavras/UFLA Cx. P. 3037 - 37.200-000 - Lavras, MG - henrique@ufla.br

${ }^{3}$ Discente de graduação em Medicina Veterinária na Universidade Federal de Lavras/UFLA - Cx. P. 3037 - $37.200-000$ - Lavras, MG. 


\section{MATERIAL E MÉTODOS}

\section{Isolados de Aeromonas hydrophila}

Os isolados bacterianos utilizados foram provenientes do banco de bactérias do Laboratório de Doenças de Organismos Aquáticos da Universidade Federal de Lavras, obtidos nos anos de 2002 a 2004. Foram utilizados 38 isolados oriundos de pescado fresco destinado ao consumo humano, 41 de casos clínicos de septicemia hemorrágica em peixes e 21 de água de cultivo de peixes, totalizando 100 isolados de $A$. hydrophila. Os isolados de pescado fresco foram obtidos em feiras livre do município de Lavras, enquanto os isolados de casos clínicos de septicemia hemorrágica e água de cultivo de peixes procederam de 12 pisciculturas, localizadas em 7 municípios distintos dos Estados de Minas Gerais, Rio de Janeiro e Rio Grande do Sul (tabela 1). As amostras de referência Pseudomonas aeruginosa (ATCC 27853) e Staphylococcus aureus (ATCC 25923) foram utilizadas como controle de qualidade e repetibilidade para cada dia de teste (NCCLS, 1997).

\section{Oxitetraciclina}

Foi utilizado o dihidrato de oxitetraciclina (Sigma, USA), dissolvido em $\mathrm{HCl} 1 \mathrm{M}$ e água destilada, com $\mathrm{pH}$ ajustado, por meio de $\mathrm{NaOH} 1 \mathrm{~N}$, para 7,0. Soluções estoque $(8 \mathrm{mg} / \mathrm{mL})$ deste antibiótico foram filtradas em membrana $0,22 \mu \mathrm{m}$ e utilizadas apenas no dia de preparo.

\section{Concentração Inibitória Mínima (MIC)}

O MIC foi determinado utilizando-se o método de macrodiluição em caldo, conforme recomendado pelo National Committee for Clinical Laboratories Standards (NCCLS, 1997). Foi utilizado o caldo Mueller-Hinton (Biolife, Itália) suplementado com cátions divalentes cálcio (100 mg/mL) e magnésio $(50 \mathrm{mg} / \mathrm{mL})$. Diluições seriadas de base dois foram realizadas, obtendo concentrações de oxitetraciclina nos tubos variando de 800 a $0,39 \mu \mathrm{g} / \mathrm{mL}$. Os isolados testados foram repicados em Agar soja tripticaseína (TSA, Biolife, Itália) e incubados a $30^{\circ} \mathrm{C}$ por 24 horas. A densidade da suspensão bacteriana foi ajustada para aproximadamente $10^{8} \mathrm{UFC} / \mathrm{mL}$ comparando com a escala 0,5 de MacFarland (BioMeriéux, França). Esta suspensão foi diluída 1:10 em solução salina estéril 0,85\% e, posteriormente, uma alíquota de $5 \mu \mathrm{L}$ foi inoculada em cada tubo $\left(10^{4} \mathrm{UFC} /\right.$ tubo). A leitura foi realizada após o período de incubação de 24 horas a $30^{\circ} \mathrm{C}$. O valor de $\mathrm{MIC}$ considerado foi a menor concentração de antibiótico capaz de inibir visualmente o crescimento bacteriano.

TABELA 1 - Isolados de Aeromonas hydrophila selecionados para determinação da concentração inibitória mínima por fonte, espécie de peixe e origem geográfica.

\begin{tabular}{|c|c|c|c|}
\hline Fonte & Espécie & Origem geográfica & Número de amostras \\
\hline Pescado Fresco $^{1}$ & & Lavras/MG & 38 \\
\hline Caso clínico ${ }^{3}$ & Tilápia (Oreochromis niloticus) & Esmeraldas/MG & 12 \\
\hline Caso clínico & Piracanjuba (Brycon orbignyanus) & Itutinga/MG & 3 \\
\hline Caso clínico & Tilápia $(O$. niloticus $)$ & Itutinga/MG & 7 \\
\hline Caso clínico & Tilápia (O. niloticus) & Lavras/MG & 1 \\
\hline Caso clínico & Tilápia (O. niloticus) & Paraíba do Sul/RJ & 8 \\
\hline Caso clínico & Jundiá (Rhamdia quelen) & Passo Fundo/RS & 10 \\
\hline Água ${ }^{4}$ & & Itutinga/MG & 4 \\
\hline Água & & Itutinga/MG & 4 \\
\hline Água & & Lavras/MG & 4 \\
\hline Água & & Perdões/MG & 5 \\
\hline Água & & Três Pontas/MG & 3 \\
\hline \multirow[t]{2}{*}{ Agua } & & Três Pontas/MG & 1 \\
\hline & & TOTAL & 100 \\
\hline
\end{tabular}

1- Bactérias obtidas de pescado fresco eviscerado destinado ao consumo humano;

2- Espécies: Curimba (Prochilodus scrofa) (18), Mandi amarelo (Pimelodus maculatus) (14), Piau (Leporinus

friderici) (2) e Tilápia (O. niloticus) (4);

3- Bactérias isoladas a partir de tecido renal de peixes com septicemia hemorrágica;

4- Bactérias isoladas de fontes ambientais como água de tanques de cultivo e água de abastecimento. 


\section{Definição de resistência e susceptibilidade}

Foi utilizada a definição proposta por Bruun et al. (2000) cuja resistência in vitro é determinada quando um conjunto de isolados de uma mesma espécie bacteriana, submetidos ao teste de MIC, divide-se em dois grupos com valores de inibição distintos. Esta separação permite a classificação dos isolados em resistentes (grupo com maiores valores de MIC) e sensíveis (grupos com menores valores de $\mathrm{MIC})$.

\section{RESULTADOS E DISCUSSÃO}

O agrupamento dos valores de MIC está representado na Figura 1. Houve agrupamento dos isolados em duas categorias: 86 isolados com valores de
MIC entre 0,78 a 12,5 $\mu \mathrm{g} / \mathrm{mL}$ (sensíveis) e 14 isolados com valores MIC entre 100 a $800 \mu \mathrm{g} / \mathrm{mL}$ (resistentes). A ocorrência de $14 \%$ de isolados resistentes indica uma freqüência baixa, porém, significativa, considerando que a mesma pode aumentar com a continuidade do uso do antibiótico devido à seleção dos clones resistentes.

A análise individual das fontes avaliadas (pescado, caso clínico de septicemia hemorrágica e água de cultivo de peixes) indica que não houve variação entre elas, ou seja, a distribuição dos valores de inibição dos isolados foi semelhante (Figura 2). Foram resistentes à oxitetraciclina, $18 \%, 15 \%$ e $5 \%$ dos isolados de $A$. hydrophila obtidos, respectivamente, de pescado, caso clínico de septicemia hemorrágica e água de cultivo de peixes.

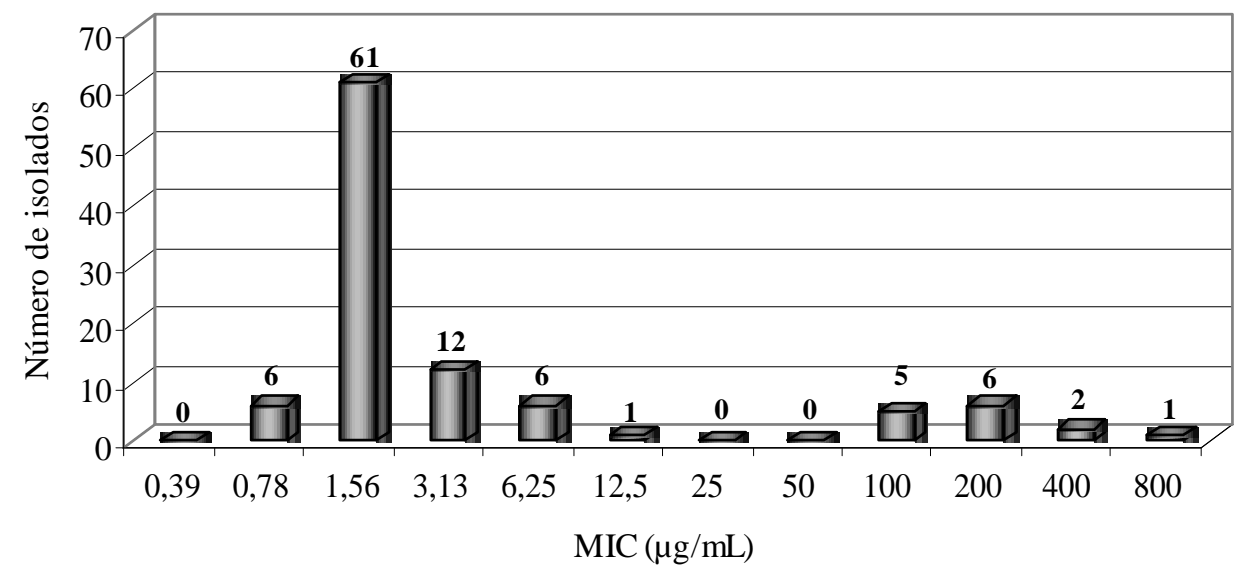

FIGURA 1 - Distribuição global dos resultados de MIC de oxitetraciclina para Aeromonas hydrophila.

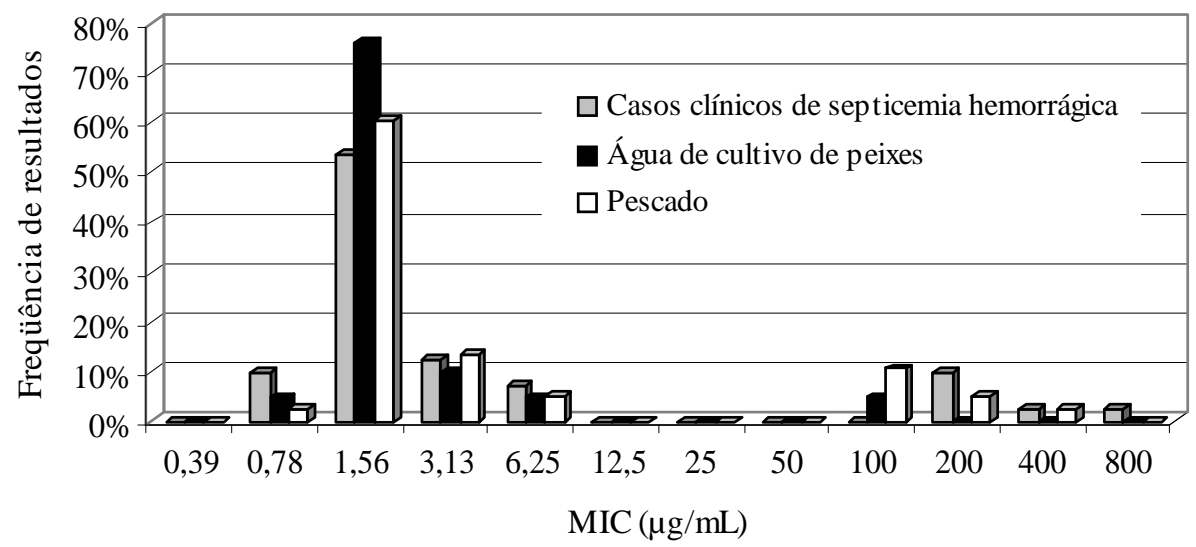

FIGURA 2 - Freqüência de resultados de MIC de oxitetraciclina para Aeromonas hydrophila oriunda de pescado, água de cultivo e caso clínico de septicemia hemorrágica em peixes.

Ciênc. agrotec., Lavras, v. 30, n.6, p. 1190-1195, nov./dez., 2006 
$\mathrm{Na}$ maioria das pisciculturas analisadas os isolados de A. hydrophila comportaram-se como sensíveis à oxitetraciclina (Tabela 2). Contudo, para algumas localidades, houve uma proporção elevada de isolados resistentes em relação ao total de isolados analisados, como nas pisciculturas 2,11. Na piscicultura 2, localizada em Paraíba do Sul (RJ), todos os isolados foram obtidos de casos clínicos de septicemia hemorrágica em tilápia e à época do isolamento o antibiótico oxitetraciclina era utilizado para controle e profilaxia de doenças bacterianas nos peixes. A associação de nível elevado de resistência à oxitetraciclina e histórico de uso da droga nesta piscicultura reforça a hipótese de que a resistência a antibióticos é variada entre ambientes e regiões, dependendo principalmente da pressão de seleção imposta ao ecossistema.

A elevação da resistência a este antibiótico por bactérias presentes nos ambientes aquáticos é uma realidade mundial, devido à facilidade das mesmas em adquirir ou transferir genes de resistência (GOÑI-URRIZA et al., 2000; RHODES et al., 2000). O uso contínuo de oxitetraciclina pode causar aumento da freqüência de isolados bacterianos resistentes e aumentar quantitativamente a resistência, dificultando tratamentos futuros e elevando o risco para a cadeia alimentar humana. No Brasil não há restrição ao uso de oxitetraciclina, sendo este, bastante comum em pisciculturas comerciais para o controle de surtos de doenças bacterianas e como medida profilática, o que pode agravar tal situação.
Existem poucos relatos de valores de MIC para os antibióticos comumente utilizados em aquiicultura. Valores de MIC de oxitetraciclina inferiores a $2 \mathrm{mg} / \mathrm{mL}$ (MOTYL et al., 1985) e valores elevados de 64 a $2048 \mathrm{mg} / \mathrm{mL}$ (MIRANDA \& ZEMELMAN, 2002) foram descritos. Não há relatos de trabalhos avaliando MIC de oxitetraciclina para um número elevado de isolados de A. hydrophila. O NCCLS (1997), comitê responsável pela padronização das metodologias de determinação de resistência a antibióticos fornece valores de referência de MIC apenas para bactérias de interesse clínico humano. A família Enterobacteriaceae, constituída de representantes Gram negativos com ampla distribuição ambiental, pode servir de parâmetro de comparação para A. hydrophila. Os valores de MIC de tetraciclina para classificação como sensível e resistente para bactérias desta família são, respectivamente, $\leq 4 \mathrm{mg}$ / $\mathrm{mL}$ e $>16 \mathrm{mg} / \mathrm{mL}$, próximo ao encontrado neste estudo para Aeromonas hydrophila. Em nosso conhecimento, este é o primeiro estudo de MIC para oxitetraciclina para a espécie Aeromonas hydrophila no Brasil.

Além de poucos relatos disponíveis na literatura, não há uma padronização suficiente da metodologia de MIC que permite a comparação para bactérias de origem aquática e ou associadas a hospedeiros heterotermos. Diversas fontes de variação podem interferir nos valores de MIC para determinado antibiótico, tais como a forma de diluição da droga, o tipo de meio de cultura utilizado, a padronização do inóculo bacteriano e a temperatura de incubação (BRUUN et al., 2000; ALDERMAN \& SMITH,

TABELA 2 - Freqüência de isolados de Aeromonas hydrophila resistentes e sensíveis à oxitetraciclina, oriundos de pisciculturas de produção de tilápias do Nilo.

\begin{tabular}{clccc}
\hline Piscicultura & Localização & $\begin{array}{c}\text { Número de } \\
\text { isolados }\end{array}$ & $\begin{array}{c}\text { MIC } \leq \mathbf{1 2 , 5} \boldsymbol{\mu g} / \mathbf{m L} \\
\text { (sensíveis) }\end{array}$ & $\begin{array}{c}\text { MIC } \geq \mathbf{1 0 0 \mu} \mathbf{\mu g} / \mathbf{m L} \\
\text { (resistentes) }\end{array}$ \\
\hline 1 & Esmeraldas/MG & 12 & $100 \%$ & $0 \%$ \\
2 & Paraíba do Sul/RJ & 8 & $25 \%$ & $75 \%$ \\
3 & Passo Fundo/RS & 10 & $100 \%$ & $0 \%$ \\
4 & Itutinga/MG & 10 & $100 \%$ & $0 \%$ \\
5 & Lavras/MG & 1 & $100 \%$ & $0 \%$ \\
6 & Perdões/MG & 5 & $100 \%$ & $0 \%$ \\
7 & Lavras/MG & 1 & $100 \%$ & $0 \%$ \\
8 & Lavras/MG & 3 & $100 \%$ & $0 \%$ \\
9 & Itutinga/MG & 4 & $100 \%$ & $0 \%$ \\
10 & Itutinga/MG & 4 & $100 \%$ & $0 \%$ \\
11 & Três Pontas/MG & 1 & $0 \%$ & $100 \%$ \\
12 & Três Pontas/MG & 3 & $100 \%$ & $0 \%$ \\
$13 *$ & Lavras & 38 & $82 \%$ & $18 \%$ \\
\hline
\end{tabular}

* Pescado oriundo de rio. 
2001). A temperatura, por exemplo, pode exercer efeitos na estabilidade dos agentes antimicrobianos, fisiologia e metabolismo bacteriano e nas bases genéticas de regulação e expressão gênica, afetando os resultados de concentração inibitória mínima (MICHEL \& BLANC, 2001). Adicionalmente, isolados de uma mesma espécie bacteriana, adaptados diferencialmente a climas tropicais ou temperados podem apresentar características distintas de crescimento in vitro. Para bactérias de ambientes aquáticos existem recomendações para determinação do MIC em temperaturas de cultivo de 22 a $30^{\circ} \mathrm{C}$, sem haver até o momento uma avaliação crítica dessa variação na temperatura de incubação. Portanto, há necessidade de desenvolver métodos de referência para a determinação da susceptibilidade aos agentes antimicrobianos por bactérias associadas a doenças de peixes, permitindo a comparação entre diferentes relatos na literatura (ALDERMAN \& SMITH, 2001; SMITH, 2001).

\section{CONCLUSÃO}

Os resultados descritos demonstram que o nível de resistência à oxitetraciclina foi variado nos isolados analisados, não havendo contudo diferença entre as fontes estudadas (pescado fresco, água de cultivo e caso clínico de septicemia hemorrágica). A variação demonstrada pode representar um risco de seleção de linhagens bacterianas resistentes no ambiente com o uso de oxitetraciclina como forma de tratamento e prevenção de doenças bacterianas em peixes.

\section{REFERÊNCIAS BIBLIOGRÁFICAS}

ALDERMAN, D. J.; SMITH, P. Development of draft protocols of standard reference methods for antimicrobial agent susceptibility testing of bacteria associated with fish diseases. Aquaculture, Amsterdam, v. 196, p. 211-243, 2001.

BRUUN, M. S.; SCHMIDT, A. S.; MADSEN, L.; DALSGAARD, I. Antimicrobial resistance patterns in danish isolates of Flavobacterium psychrophilum. Aquaculture, Amsterdam, v. 187, p. 201-212, 2000.

GOÑI-URRIZA, M.; CAPDEPUY, M.; ARPIN, C.; RAYMOND, N.; CAUMETTE, P.; QUENTIN, C. Impact of a urban effluent on antibiotic resistance of riverine Enterobacteriaceae and Aeromonas spp. Applied and Environmental Microbiology, Washington, v. 66, n. 1, p. 125-132, Jan. 2000.
JANDA, J. M.; ABBOTT, S. L. Evolving concepts regarding the genus Aeromonas: an expanding panorama of species, disease presentations, and unanswered questions. Clinical Infectious Diseases, [S.1.], v. 27, p. 332-344, Mar. 1998.

KIROV, S. M.; TASSELL, B. C.; SEMMLER, A. B. T.; O'DONOVAN, L. A.; RABAAN, A. A.; SHAW, J. G. Lateral flagella and swarming motility in Aeromonas Species. Journal of Bacteriology, [S.1.], v. 184, n. 2, p. 547-555, Jan. 2002.

MERINO, S.; RUBIRES, X.; KNOCHEL, S.; TOMÁS, J. M. Emerging pathogens: Aeromonas spp. International Journal of Food Microbiology, Amsterdam, v. 28, p. 157168, 1995.

MICHEL, C.; BLANC, G. Minimal inhibitory concentration methodology in aquaculture: the temperature effect. Aquaculture, Amsterdam, v. 196, p. 311-318, 2001.

MIRANDA, C. D.; ZEMELMAN, R. Bacterial resistance to oxytetracycline in chilean salmon farming. Aquaculture, Amsterdam, v. 212, p. 31-47, 2002.

MOTYL, M. R.; McKINLEY, G.; JANDA, J. M. In vitro susceptibilities of Aeromonas hydrophila, Aeromonas sobria, and Aeromonas caviae to 22 antimicrobial agents. Antimicrobial Agents and Chemotherapy, London, v. 28, n. 1, p. 151-153, July 1985.

NATIONAL COMMITTEE FOR CLINICAL LABORATORY STANDARDS. Methods for dilution antimicrobial susceptibility tests for bacteria that grow aerobically. 4. ed. Villanova, 1997.

RHODES, G.; HUYS, G.; SWINGS, J.; McGANN, P.; HINEY, M.; SMITH, P.; PICKUP, R. W. Distribution of oxytetracycline resistance plasmids between aeromonads in hospital and aquaculture environments: implication of Tn1721 in dissemination of the tetracycline resistance determinant tet A. Applied and Environmental Microbiology, Amsterdam, v. 66, n. 9, p. 3883-3890, Sept. 2000.

ROUBACH, R.; CORREIA, E. S.; ZAIDEN, S.; MARTINO, R. C.; CAVALLI, R. O. Aqüicultura brasileira. Panorama da Aqüicultura, Rio de Janeiro, v. 13, n. 76, p. 47-57, mar./abr. 2003. 
SMITH, P. Accuracy, precision and meaning of antimicrobial agent susceptibility testing of bacteria associated with fish diseases. Aquaculture, Amsterdam, v. 196, p. 253-266, 2001.
WORLD HEALTH ORGANIZATION. Microbial fact sheets. In: Guidelines for drinking-water quality. 3. ed. Geneva, 2004. v. 1. 